\title{
A Comparative Study of Effectiveness of Ultrasound-Guided Transversus Abdominis Plane (TAP) Block vs Epidural Analgesia for Post-Operative Pain Relief in Lower Abdominal Surgeries
}

\author{
Santosh Bhagasra', Neelam Meena' ${ }^{2}$, Vikas Rajpurohit ${ }^{3}$ \\ ${ }^{1}$ PG Anaesthesia, Department of Anaesthesia and Critical Care, Dr. S.N.M.C Jodhpur, Rajasthan, India, ${ }^{2}$ Associate Professor, Department of Anaesthesia and \\ Critical Care, Dr. S.N.M.C. Jodhpur, India, ${ }^{3}$ Associate Professor, Department of Anaesthesia and Critical Care, Dr. S.N.M.C. Jodhpur, Rajasthan, India.
}

\section{Abstract}

Background: An increase in the use of regional anesthesia techniques for postoperative pain relief for analgesia following lower abdominal surgeries. Epidural anesthesia considered as the "gold standard" has been established to provide excellent analgesia as well as attenuation of neurogenic contribution to inflammation. The TAP block provides reliable somatic analgesia in lower abdominal incision surgeries. Use of ultrasound helps incorrect localization of the plane and accurate placement of the needle and catheter. Subjects and Methods: In TAP group under USG guidance $20 \mathrm{ml} 0.2 \%$ Inj. Ropivacaine was deposited on each side of the abdominal wall. In Epidural group $10 \mathrm{ml}$ of $0.2 \%$ Inj. Ropivacaine was administered at skin closure. Results: Systolic and diastolic blood pressure levels were significantly lower in group B as compared to group A $(\mathrm{p}<0.05)$. . VAS score was significantly higher in group B as compared to group A $(\mathrm{P}<0.05)$. It was observed that a significantly higher number of patients in epidural group required rescue analgesia and at higher dosages ( $\mathrm{p}<0.05)$. Conclusion: TAP block has almost no complications, keeps the patient hemodynamically stable and offers a good early postoperative analgesia (till 24 hours) when compared to a more accepted modality like epidural analgesia.

Keywords: TAP; Transversus Abdominis Plane, VAS; Visual analogue score, ASA; American Society of Anaesthesiologists.

Corresponding Author: Dr. Neelam Meena, Associate professor, Department of Anaesthesia and Critical Care, Dr. S.N.M.C. Jodhpur, Rajasthan, India.

Email: drsantoshbhagasra@gmail.com

Received: February 2020

Accepted: February 2020

\section{Introduction}

Since time immemorial, pain has remained the most significant issue making patients to seek medical consultation. In the postoperative period, potent analgesia is required not only to make the patients bear the surgical stress, but it also helps in early ambulation and thereby limits many complications such as lung atelectasis and deep vein thrombosis. ${ }^{[1-4]}$ The opioid analgesics are the most commonly parenteral agents to take care of postoperative pain but the problem of respiratory depression associated with them remains to be considered. ${ }^{[5]}$ For lower abdominal surgeries, epidural analgesia has been the gold standard and time-tested technique for providing postoperative analgesia, but contraindications for the same would warrant the need for other equally good analgesic techniques. Transversusabdominis plane (TAP) block is an effective method of blocking the sensory afferents supplying the anterior abdominal wall. There are two types of TAP blocks described: posterior and subcostal. Single-shot posterior TAP blocks have been shown to provide analgesia after lower abdominal surgery. ${ }^{[6-12]}$

Rafi originally described the transversus abdominis plane (TAP) block. ${ }^{[13]}$ TAP catheter-based techniques are relatively new techniques that have been used as a part of multimodal analgesia for abdominal surgery, ${ }^{[7]}$ cesarean section, ${ }^{[14]}$ abdominal hysterectomy, ${ }^{[9]}$ and prostatectomy. ${ }^{[6]}$ There are regional anaesthesia techniques that provide analgesia to the skin and muscles of the anterior abdominal wall. ${ }^{[18]}$ Ultrasound for guiding the TAP block was first described by Hebbard et al. ${ }^{[15]}$ Their advantages over neuraxial techniques are absence of hemodynamic instability, early mobilization, and not requiring prolonged urinary catheterization. Despite a low-risk of complications and a high success rate, it is an underutilized technique. ${ }^{[16]}$

Till date, only four randomized trials have been performed comparing the analgesic efficacy of epidural and TAP for abdominal surgeries, with none being able to definitively conclude the superiority of one over the other. ${ }^{[17]}$ Hence the present study has done at our tertiary care center to explore the postoperative analgesic efficacy of Posterior TAP Block in comparison to the previously established Epidural analgesia in patients undergoing lower abdominal and gynecological surgeries under general anaesthesia.

Transversus abdominis plane block is one such abdominal field block which can access the number of abdominal wall nerves. ${ }^{[18]}$ It provides widespread analgesia through a single entry point when using a landmark-based technique. ${ }^{[19]}$ The advent of USG has increased the efficacy multifold as it 
provides better localization and deposition of the local anaesthetic. ${ }^{[19]}$

The aim of a TAP block is to deposit local anaesthetic in the plane between the internal oblique and transversus abdominis muscles targeting the nerves in this plane. This leads to interruption of the nerve supply of abdominal skin, muscles and parietal peritoneum [Figure 1], but a dull visceral pain is still experienced in entering the peritoneal cavity due to inflammation resulting from surgical insult.

\section{Aims and Objectives}

The aim of the study is to compare the postoperative pain relief offered by ultrasound-guided TAP block with epidural analgesia in the first 24 hours after lower abdominal surgeries under general anesthesia. To study and compare supplementary analgesia requirement, hemodynamic changes and major complications in the first 24 postoperative hours in both the groups.

\section{Subjects and Methods}

It was an analytical study comparing two different modalities of postoperative pain relief in patients undergoing lower abdominal surgeries.

\section{Source of Data:}

This study was conducted at The Department of Anaesthesiology and Critical Care in Dr. S.N. Medical College \& Associated Group of Hospital after getting approval from the ethical committee on patients undergoing lower abdominal. A written and informed consent was taken from patient.

\section{Method of Collection of Data}

Randomization was done by computer-generated random numbers using research randomizer computer software.

Inclusion criteria:

- Age 18 -80 years

- Patients ASA grade I, II.

- Patients with weight $50-90 \mathrm{kgs}$.

- Patients undergoing elective lower abdominal surgeries under GA.

\section{Exclusion Criteria:}

- Patient refusal

- Patients ASA grade III ,IV

- Age> 80 years of.

- Patients on chronic opioid usage

- Patients with allergies to local anaesthetics

- Patients with significant coexisting diseases like ischemic heart disease, hypertension, cardiovascular diseases, impaired renal functions and severe liver disease.

- Any existence of contraindications to regional anaesthesia in the presence of anti-platelet, anticoagulant drug use, bleeding/clotting disorders

- Evidence of any neurological impairment. Obese patients $(\mathrm{BMI}=30-39.9 \mathrm{~kg} / \mathrm{sq}$ metre or more $)$ Cases with failed blocks.

Sample Size Calculation

Sample size calculation was based on previous study 21 with The primary outcome measured in this study was the pain score at rest (i.e VAS) at 24 hours during the 0-24 hours postoperative period, the severity of pain. The $\alpha$ error used for this analysis was assumed at 0.05 and power of the study at $(1-\beta 2) 80 \%$ so sample size was calculated to be approximately 35 in each group.

\section{Statistical analysis:}

They performed using SPSS for Windows (version 22, SPSS Inc., Chicago, IL, USA). The student's t-test was used to compare the continuous variables between the groups. Categorical variables were analyzed using the $\chi 2$ test or Fisher's exact test, as appropriate. A P value of $<0.05$ was considered statistically significant. Data are presented as means \pm standard deviation (SD), numbers, or percentage.

Randomization: Randomization was done by computergenerated random numbers using research randomizer computer software.

A total of 70 patients were grouped into two equal groups by computer-generated numbers

1. Group A-(TAP BLOCK)

2. Group B- (EPIDURAL BLOCK)

\section{Methods}

Prior to administering general anaesthesia, informed consent was confirmed. Baseline readings of the heart rate, respiratory rate, non-invasive blood pressure, pulse oximetry were recorded.

The patient was pre-medicated with Inj. Midazolam 0.05 $\mathrm{mg} / \mathrm{kg}$ and Inj. Fentanyl $2 \mathrm{mcg} / \mathrm{kg}$; Induction of General Anaesthesia was done with Inj. Propofol $2 \mathrm{mg} / \mathrm{kg}$ and muscle relaxant used for orotracheal intubation were Inj. Atracurium $0.4-0.5 \mathrm{mg} / \mathrm{kg}$. Anaesthesia was maintained with sevoflurane with oxygen and inj atracurium $0.1 \mathrm{mg} / \mathrm{kg}$. The duration of surgery was recorded. Intraoperative baseline HR, blood pressure, pulse oximetry was recorded.

Group A: The patient was positioned supine. After skin closure, under strict asepsis and under USG guidance, $20 \mathrm{ml}$ $0.2 \%$ ropivacaine was injected on each side of the abdominal wall in the plane between transversus abdominis and internal oblique muscles after hydro dissection with $0.9 \%$ saline $(2-5$ $\mathrm{ml})$. The needle used was $22 \mathrm{G}$ Quincke's needle connected to a $10 \mathrm{~cm}$ intravenous line extension for ease of drug administration. The portable Ultrasound machine used was Sonosite with the linear high-frequency probe.

Group B:The patient was positioned in lateral decubitus or sitting position and under strict asepsis, lumbar epidural space was reached by loss of resistance to air technique and catheter was placed at vertebral levels (as clinically indicated). After injection of a test dose of $2 \mathrm{ml}$ of $2 \%$ lignocaine with 1:200,000 epinephrine, the patient was induced and the surgery continued.10 $\mathrm{ml}$ of $0.2 \%$ ropivacaine was administered at skin closure.

Postoperative monitoring (study period): After completion of surgery under general anaesthesia, all patients were observed in the postoperative recovery area. All the patients were administered oxygen via a face mask at the rate of $6 \mathrm{~L} / \mathrm{min}$ and was covered with blankets.

Postoperative heart rate, blood pressure, pulse oximetry and VAS score for pain were recorded. 


\begin{tabular}{|c|c|c|c|c|}
\hline \multicolumn{5}{|c|}{ Table 1: Demographic Table } \\
\hline & Group A & GroupB & $\begin{array}{l}\text { T } \\
\text { Value } \\
\end{array}$ & $\begin{array}{l}\text { P- } \\
\text { Value } \\
\end{array}$ \\
\hline Age & $43.05+11.35$ & $45.77+11.15$ & 1.009 & 0.316 \\
\hline $\begin{array}{l}\text { Sex (Male, Female } \\
\text { Ration }\end{array}$ & $15: 20$ & $10: 25$ & & 0.212 \\
\hline ASA & $21: 14$ & $20: 15$ & & $>0.05$ \\
\hline WEIGHT & $60.25+5.84$ & $62.05+5.04$ & 1.379 & 0.172 \\
\hline
\end{tabular}

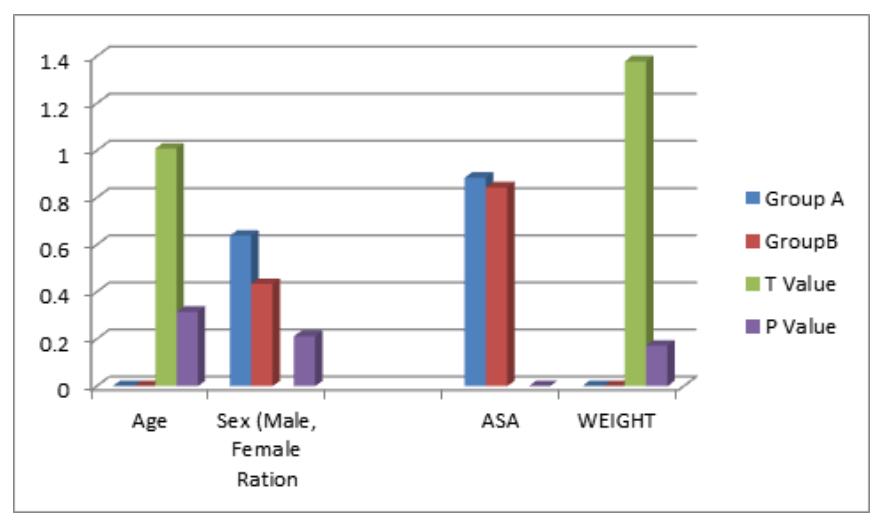

Figure 1: Comparison of demographic variables.

Table 2: Comparison of MAP $(\mathrm{mmHg})$

\begin{tabular}{|l|l|l|l|l|}
\hline \multirow{2}{*}{ Time } & \multicolumn{2}{|l|}{ MBP $(\mathbf{m m H g})$} & \multirow{2}{*}{ value } & $\begin{array}{l}\text { p- } \\
\text { value }\end{array}$ \\
\cline { 2 - 3 } & $\begin{array}{l}\text { Tap Block } \\
(\text { Mean } \pm \text { SD })\end{array}$ & $\begin{array}{l}\text { Epidural } \\
\text { Block } \\
(\text { Mean } \pm \text { SD })\end{array}$ & & \\
\hline Baseline & $95.82 \pm 4.14$ & $95.51 \pm 5.18$ & 0.28 & 0.78 \\
\hline $\begin{array}{l}\text { Before } \\
\text { block }\end{array}$ & $95.4 \pm 4.03$ & $94.8 \pm 5.09$ & 0.546 & 0.586 \\
\hline After block & $95 \pm 4.08$ & $94.45 \pm 5.20$ & 0.485 & 0.629 \\
\hline 30min & $94.68+3.31$ & $91.2+4.95$ & 3.458 & 0.0009 \\
\hline 2hrs & $97.77 \pm 3.97$ & $90.62 \pm 5.05$ & 6.575 & $<0.0001$ \\
\hline 4 hrs & $98.71 \pm 3.29$ & $90.88 \pm 5.05$ & 7.679 & $<0.0001$ \\
\hline 6hrs & $98.97 \pm 3.56$ & $91.51 \pm 4.90$ & 7.271 & $<0.0001$ \\
\hline 8 hrs & $99.11 \pm 3.32$ & $93.28 \pm 4.51$ & 6.151 & $<0.0001$ \\
\hline $10 \mathrm{hrs}$ & $96.42 \pm 3.22$ & $95.25 \pm 4.85$ & 1.189 & 0.238 \\
\hline $12 \mathrm{hrs}$ & $97.37 \pm 3.42$ & $95.57 \pm 4.89$ & 1.773 & 0.08 \\
\hline $18 \mathrm{hrs}$ & $97.77 \pm 3.30$ & $95.91 \pm 4.91$ & 1.856 & 0.067 \\
\hline $24 \mathrm{hrs}$ & $98.51 \pm 3.86$ & $96.77 \pm 4.37$ & 1.768 & 0.081 \\
\hline
\end{tabular}

\section{Unpaired t-test}

The table shows that from 30 minutes to 8 hours, mean arterial pressure levels were significantly lower in the Epidural group as compared to TAP Group $(\mathrm{p}<0.05)$.

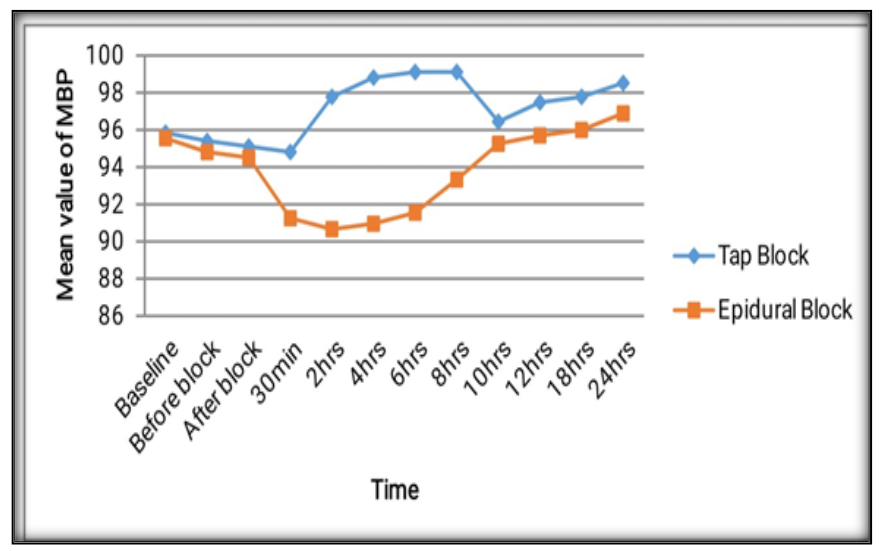

Figure 2: Comparison of MAP (mmHg)

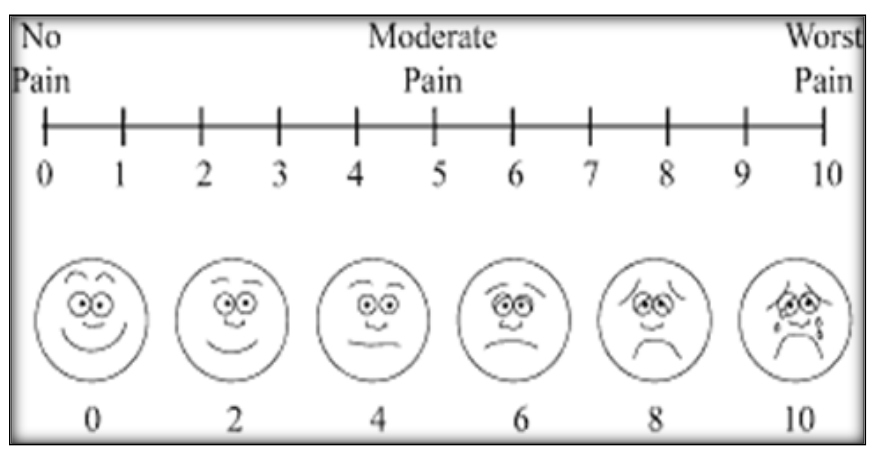

Vas Score

Table 3: Comparison of VAS Score at various time intervals
\begin{tabular}{|l|l|l|l|l|}
\hline \multirow{2}{*}{ Time } & VAS Score & $\begin{array}{l}\text { t } \\
\text { value }\end{array}$ & $\begin{array}{l}\text { p- } \\
\text { value }\end{array}$ \\
\cline { 2 - 5 } & $\begin{array}{l}\text { Tap Block } \\
\text { (Mean+SD) }\end{array}$ & $\begin{array}{l}\text { Epidural Block } \\
\text { (Mean+SD) }\end{array}$ & & \\
\hline $0 \mathrm{~min}$ & $0.08+0.75$ & $0.94+0.68$ & 0.827 & 0.411 \\
\hline $30 \mathrm{~min}$ & $0.08+0.75$ & $1.05+0.59$ & 1.581 & 0.118 \\
\hline $2 \mathrm{hrs}$ & $1.28+0.45$ & $2.4+0.55$ & 9.177 & $<0.0001$ \\
\hline $4 \mathrm{hrs}$ & $2.17+0.56$ & $3.31+0.63$ & 7.963 & $<0.0001$ \\
\hline $6 \mathrm{hrs}$ & $3.54+0.91$ & $3.62+0.73$ & 0.432 & 0.667 \\
\hline $8 \mathrm{hrs}$ & $2.97+0.45$ & $3.85+0.87$ & 5.298 & $<0.001$ \\
\hline $10 \mathrm{hrs}$ & $3.2+0.53$ & $3.17+0.51$ & 0.228 & 0.819 \\
\hline $12 \mathrm{hrs}$ & $3.25+0.65$ & $3.8+0.90$ & 2.88 & 0.005 \\
\hline $18 \mathrm{hrs}$ & $4.45+0.98$ & $4+0.72$ & 2.215 & 0.03 \\
\hline $24 \mathrm{hrs}$ & $3.2+0.53$ & $3.25+0.56$ & 0.437 & 0.66 \\
\hline
\end{tabular}

\section{Unpaired t-test}

The table shows that postoperativelyat 2 hours, 4 hours, 8 hours and 12-hour VAS score was significantly higher in Epidural group as compared to TAP block group $(\mathrm{p}<0.05)$.

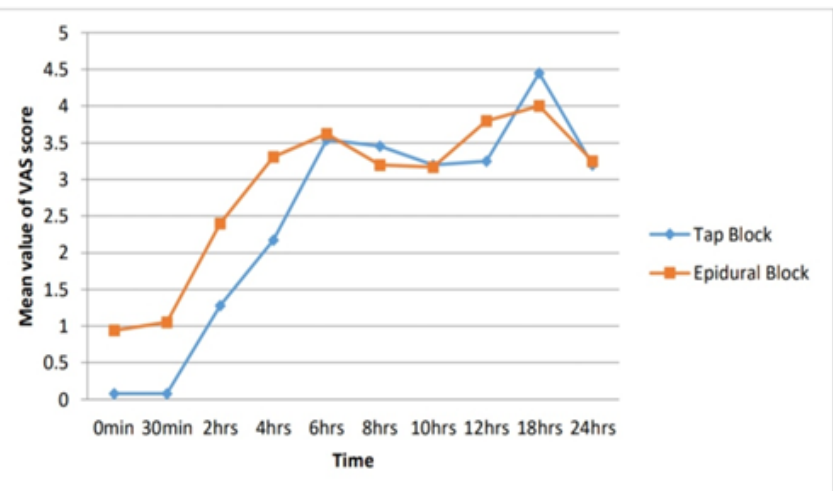

Figure 3: Comparison of VAS score at various time intervals

Table 4: Comparison of Mean duration of analgesia between groups

\begin{tabular}{|l|l|l|}
\hline Duration of analgesia (min) & Tap Block & Epidural Block \\
\hline Median & 350 & 260 \\
\hline Range & $240-360$ & $210-350$ \\
\hline Mean \pm SD & $340.51 \pm 28.24$ & $273.43 \pm 35.80$ \\
\hline t \& p value & $8.703,<0.0001$ \\
\hline
\end{tabular}

\section{Unpaired t-test}

The mean duration of analgesia was significantly longer in TAP Group as compared to Epidural Group (340.51 \pm 28.24 mins vs. $273.43 \pm 35.80 \mathrm{mins}$ ). This difference was statistically significant as per Student t-test $(\mathrm{p}<0.05)$. 


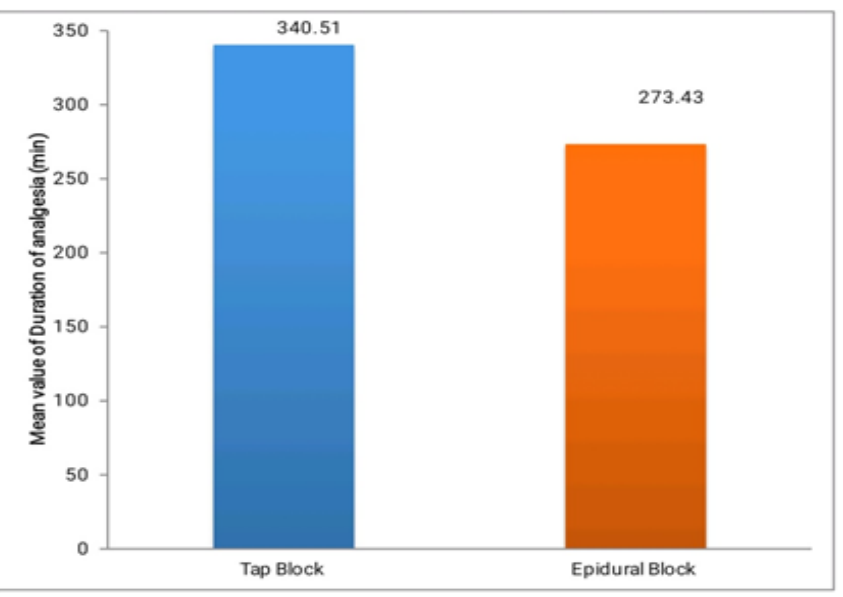

Figure 4: Duaration of Analgesia.

Table 5: Distribution of patients according to the Requirement of Rescue Analgesic

\begin{tabular}{|l|l|l|l|l|}
\hline \multirow{2}{*}{$\begin{array}{l}\text { Tramadol } \\
\text { consumption (mg) }\end{array}$} & \multicolumn{2}{|l|}{ Tap Block } & \multicolumn{2}{l|}{ Epidural Block } \\
\cline { 2 - 6 } & $\mathbf{N}$ & $\mathbf{\%}$ & $\mathbf{N}$ & $\%$ \\
\hline 100 & 10 & 28.57 & 8 & 22.86 \\
\hline 150 & 20 & 57.14 & 15 & 42.86 \\
\hline 200 & 0 & 0.00 & 10 & 28.57 \\
\hline 300 & 0 & 0.00 & 2 & 5.71 \\
\hline Mean \pm SD & $120 \pm 50.29$ & $161.42 \pm 50.12$ \\
\hline$t \& p$ value & $3.452,<0.0001$ & \multicolumn{2}{l|}{} \\
\hline
\end{tabular}

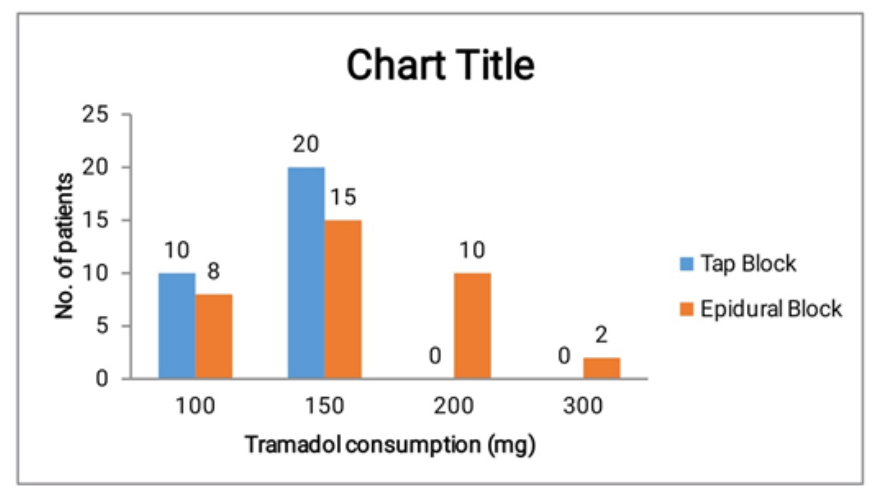

Figure 5: Tramadol Consumption.

Table 6: Comparison of Postoperative complications between groups

\begin{tabular}{|l|l|l|l|l|l|}
\hline \multirow{2}{*}{$\begin{array}{l}\text { Side } \\
\text { effects }\end{array}$} & \multicolumn{2}{|l|}{ Tap Block } & \multicolumn{2}{l|}{ Epidural Block } & \multirow{2}{*}{ p value } \\
\cline { 2 - 5 } & $\mathbf{N}$ & $\mathbf{\%}$ & $\mathbf{N}$ & $\mathbf{\%}$ & \\
\hline Nausea & 2 & 5.71 & 3 & 8.57 & $>0.05$ \\
\hline Vomiting & 1 & 2.86 & 2 & 5.71 & $>0.05$ \\
\hline Headache & 0 & 0 & 1 & 2.86 & $>0.05$ \\
\hline
\end{tabular}

\section{Discussion}

\section{Demographic variables:}

In our study there was no significant difference in the distribution of patients based on age,sex, ASA physical status and weight. ${ }^{[28]}$

\section{Duration of surgery:}

In our study, the mean duration of surgery was significantly shorter in TAP group as compared to Epidural group B $(94 \pm 17.35$ minutes vs. $100.57 \pm 26.53$ minutes). This difference was statistically not significant as per Student ttest $(\mathrm{p}>0.05)$.

\section{Vital parameters:}

Heart rate and SPO2 were comparable in both the group and it was statistically not significant as per student t-test ( $p>0.05)$.It was observed in our study that postoperatively from 30 minutes to 8 hours, systolic blood pressure levels were significantly lower in the Epidural group as compared to TAP group $(\mathrm{p}<0.05)$. Similarly, postoperatively from 30 minutes to 8 hours, diastolic blood pressure levels were significantly lower in the Epidural group as compared to TAP group $(\mathrm{p}<0.05)$.

Here, Mean arterial pressure was also significantly lower in the Epidural group as compared to TAP group $(\mathrm{p}<0.05)$ from 30 minutes to 8 hours of both the blocks. ${ }^{[20,26,27,30]}$

\section{Duration of Analgesia:}

In our study, the mean duration of analgesia was significantly higher in TAP group as compared to Epidural group B (340.51 \pm 28.24 mins vs. $273.43 \pm 35.80 \mathrm{mins})$. This difference was statistically significant as per student t-test $(\mathrm{p}<0.05)$.

The results of our study show that the analgesic efficacy of TAP block has thus been found to significantly better when compared to Epidural analgesia, both using ropivacaine $(0.2 \%)$ as the anaesthetic agent. It can be included in a multimodal analgesia regimen in place of epidural analgesia. TAP block provides selective analgesia by blocking only the anterior abdominal wall nerve innervations. Therefore, it has a better side effect profile than epidural analgesia. TAP analgesia has the least effect on the cardiovascular system and motor function of the lower limbs.

\section{Visual analog scale for pain:}

In the present study, show postoperatively at 2 hours, 4 hours, 8 hours and 12 hours VAS score was significantly higher in the Epidural group as compared to TAP Group $(\mathrm{p}<0.05){ }^{[22-26]}$

\section{The requirement of rescue analgesia:}

In our study, $10(28.57 \%)$ patients required $100 \mathrm{mg}$ of tramadol, while $20(57.14 \%)$ patient required $150 \mathrm{mg}$ of tramadol. 5 patients not required tramadol in TAP group. In epidural group $8(22.86 \%)$ patients required $100 \mathrm{mg}$ of tramadol, $15(42.86 \%)$ patients required $150 \mathrm{mg}$ of tramadol while $10(28.57 \%)$ and $2(5.71 \%)$ patients required $200 \mathrm{mg}$ and $300 \mathrm{mg}$ of tramadol respectively. It was observed that a significantly higher number of patients in the epidural group required rescue analgesic and at higher dosages $(\mathrm{p}<0.05){ }^{[22,24,26,27,30]}$

\section{Complications / Adverse effects}

In the present study, $2(5.71 \%)$ and $3(8.57 \%)$ patients in TAP group and Epidural group respectively had nausea. 1 $(2.86 \%)$ and $2(5.71 \%)$ patients in TAP group and Epidural group respectively had vomiting and $0(0 \%)$ and $2(5.71 \%)$ patients in TAP group and Epidural group respectively had a headache.The incidence of nausea \& vomiting was more in the epidural group as compared to group A, however this difference was statistically not significant as per Chi-Square test $(\mathrm{p}>0.05){ }^{[2,23,26]}$

\section{Conclusion}

In above study it was observed that postoperatively from 
30min. to $8 \mathrm{hrs}$ SBP and DBP were significantly lower in group B as compared to group A (0.05). There was a significant difference in VAS Score of group A and group B at 2 hours, 4 hours, 8 hours, \& 12 hours. VAS score was significantly higher in group B as compared to group A $(\mathrm{P}<0.05)$. It was observed that a significantly higher number of patients in epidural group required rescue analgesia and at higher dosages $(\mathrm{p}<0.05) .2(5.71 \%)$ and $3(8.57 \%)$ patients in TAP group and Epidural group respectively had nausea. 1 $(2.86 \%)$ and $2(5.71 \%)$ patients in TAP group and Epidural group respectively had vomiting and $0(0 \%)$ and $2(2.86 \%)$ patients in TAP group and Epidural group respectively had a headache. The incidence of nausea $\&$ vomiting was more in the epidural group as compared to group A, however this difference was statistically not significant as per Chi-Square test $(\mathrm{p}>0.05)$.

Based on the above findings in this study it is being summarized that ultrasound-guided Transversus abdominis plane block offers a better early (first 24 hours) postoperative analgesia when compared to Epidural analgesia in patients undergoing lower abdominal surgeries under general anesthesia. This is not only in terms of a statistically significant lower VAS scores for pain but also a lower requirement of rescue analgesia in terms of Injection tramadol in the TAP block group.

In addition the hemodynamic parameters were also found to be more stable in TAP block group with comparable heart rate and SPO2 but significantly lower incidence of hypotension with respect to the Epidural group. No complication barring postoperative nausea vomiting was observed. The incidence was lower in TAP block group but was found to be statistically insignificant.

\section{References}

1. Schug SA. the global year against acute pain. Anaesth Intensive Care. 2011;39(1):11-14.

2. Liu SS, Wu CL. Effect of postoperative analgesia on major postoperative complications: a systematic update of the evidence Anesth Analg. 2007;104(3):689-702.

3. Mhuircheartaigh RJ, Moore RA, McQuay HJ. Analysis of individual patient data from clinical trials: epidural morphine for postoperative pain. Br J Anaesth. 2009;103(6):874-881.

4. Yu N, Long X, Hernandez JRH, Succar J, Xin X, Wang X. Transversus abdominis-plane block versus local anesthetic wound infiltration in lower abdominal surgery: a systematic review and meta-analysis of randomized controlled trials. BMC Anesthesiol 2014;14:121-129.

5. Rollason V, Samer C, Piguet V. Pharmacogenetics of analgesics: toward the individualization of prescription. Pharmacogenomics.2008;9(7):905933.

6. O'Donnell BD, McDonnell JG, McShane AJ. The transversus abdominis plane (TAP) block in open retropubic prostatectomy. Reg Anesth Pain Med.2006;31: 91-95.

7. McDonnell JG, O'Donnell BD, Curley GCJ, Heffernan A, Power C, Laffey JG. The analgesic efficacy of transversus abdominis block after abdominal surgery: a prospective randomized controlled trial. Anesth Analg.2007;104:193-197.

8. McDonnell JG, Curley GCJ, Carney J. The analgesic efficacy of transversus abdominis block after caesarean delivery. Anesth Analg.2008;106:186-191.

9. Carney J, McDonnell JG, Ochana A, Bhinder R, Laffey JG. The transversus abdominis plane block provides effective postoperative analgesia in patients undergoing total abdominal hysterectomy. Anesth Analg2008;107: 2056-60
10. El-Dawlatly AA, Turkistani A, Kettner SC et al. Ultrasound-guided transversus abdominis plane block: description of a new technique and comparison with conventional systemic analgesia during laparoscopic cholecystectomy. Br J Anaesth.2009;102:763-7.

11. Niraj G, Searle A, Mathews M, et al. The analgesic efficacy of ultrasound-guided transversus abdominis plane (TAP) block in patients undergoing open appendicectomy. Br J Anaesth. 2009; 103: 601-5.

12. Belavy D, Cowlishaw PJ, Howes M, Phillips F. Ultrasound-guided transversus abdominis plane block for analgesia after Caesarean delivery.Br J Anaesth. 2009; 103: 726-30.

13. Rafi AN. Abdominal field block: A new approach via the lumbar triangle. Anaesthesia.2001; 56:1024-6.

14. Abdallah FW, Halpern SH, Margarido CB. Transversus abdominis plane block for postoperative analgesia after cesarean delivery performed under spinal anaesthesia? A systematic review and metaanalysis. Br J Anaesth. 2012; 109:679-87.

15. Hebbard P, Fujiwara Y, Shibata Y, Royse C. Ultrasound-guided transversus abdominis plane (TAP) block. Anaesth Intensive Care. 2007; 35:616-7.

16. Kearns RJ, Young SJ. Transversus abdominis plane blocks; a national survey of techniques used by UK obstetric anaesthetists. Int J Obstet Anesth. 2011; 20:103-4.

17. Zhang P, Deng XQ, Zhang R, Zhu T. Comparison of transversus abdominis plane block and epidural analgesia for pain relief after surgery. Br J Anaesth.2015; 114:339.

18. Mukhtar K. TAP block. J NYSORA 2009;12: 28-3.

19. Rafi AN. Abdominal field block: a new approach via lumbar triangle. Anesthesia. 2001;56(10):1024-26.

20. Levy Gal, Cordes Mark A, Farivar Alexander S, et al. Transversus abdominis Plane Block Improves Perioperative Outcome After Esophagectomy Versus Epidural. Ann Thoracic Surg. 2018;105(2):40612.

21. Ranjit S, Shrestha SK. Comparison of Ultrasound-Guided Transversus abdominis Plane Block Versus Local Wound infiltration for Postoperative Analgesia in Patients Undergoing Gynaecological Surgery Under General Anaesthesia. Kathmandu Univ Med J. 2014; 46(2):93-6.

22. Kandi Y. Efficacy of ultrasound-guided transversus abdominis plane block versus epidural analgesia in pain management following lower abdominal surgery. Ain Shams J Anesthesiol. 2015; 8:653-7.

23. Ayad S, Babazade R, Elsharkawy H, Nadar V, Lokhande C, Makarova $\mathrm{N}$ et al. Comparison of Transversus abdominis Plane Infiltration with Liposomal Bupivacaine versus Continuous Epidural Analgesia versus Intravenous Opioid Analgesia. PLoS ONE.2016; 11(4): 0153675.

24. Sinha S, Palta S, Saroa R, Prasad A. Comparison of ultrasound-guided transversus abdominis plane block with bupivacaine and ropivacaine as adjuncts for postoperative analgesia in laparoscopic cholecystectomies. Indian J Anaesth. 2016; 60(4):264-9.

25. Iyer SS, Bavishi H, Mohan CV, Kaur N. Comparison of Epidural Analgesia with Transversus abdominis Plane Analgesia for Postoperative Pain Relief in Patients Undergoing Lower Abdominal Surgery: A Prospective Randomized Study. Anesth Essays Res. 2017; 11(3):670-675.

26. Prabhu N, Bharti AK, Yadav G, Pandey V, Singh Y, et al. Evaluation of USG Guided Transversus abdominis Plane Block for Post-Operative Analgesia in Total Abdominal Hysterectomy Surgeries. J Anesth Clin Res 8:710.

27. Rao Kadam V, Van Wijk RM, Moran JI, Miller D. Epidural versus continuous transversus abdominis plane catheter technique for postoperative analgesia after abdominal surgery, Anaesth Intensive Care. 2013;41:476-81.

28. Regmi S, Srinivasan S, Badhe AS, Satyaprakash MV et al. comparison ofanalgesic efficacy of continuous bilateral transversus abdominis plane catheter unfusion with that of lumbar epidural for postoperative analgesia in patients undergoing lower abdominal surgeries. Indian J Anaesth 2019;63:462-8.

29. Tan TT, Teoh WH, Woo DC, Ocampo CE, Shah MK, Sia AT. A randomized trial of the analgesic efficacy of ultrasound-guided transversus abdominis plane block after caesarean delivery under general anaesthesia. Eur J Anaesthesiol. 2012; 29(2):88-94.

30. Wu Y, Liu F, Tang $\mathrm{H}$, et al. The analgesic efficacy of subcostal transversus abdominis plane block compared with thoracic epidural analgesia and intravenous opioid analgesia after radical gastrectomy, Anesth Analg.2013;117:507-13. 
Copyright: (C) the author(s), 2020. It is an open-access article distributed under the terms of the Creative Commons Attribution License (CC BY 4.0), which permits authors to retain ownership of the copyright for their content, and allow anyone to download, reuse, reprint, modify, distribute and/or copy the content as long as the original authors and source are cited.

How to cite this article: Bhagasra S, Meena N, Rajpurohit V. A Comparative Study of Effectiveness of Ultrasound Guided Transversus Abdominis Plane (TAP) Block vs Epidural Analgesia for Post-Operative Pain Relief in Lower Abdominal Surgeries. Acad. Anesthesiol. Int. 2020;5(1):103-108.

DOI: dx.doi.org/10.21276/aan.2020.5.1.21

Source of Support: Nil, Conflict of Interest: None declared. 